
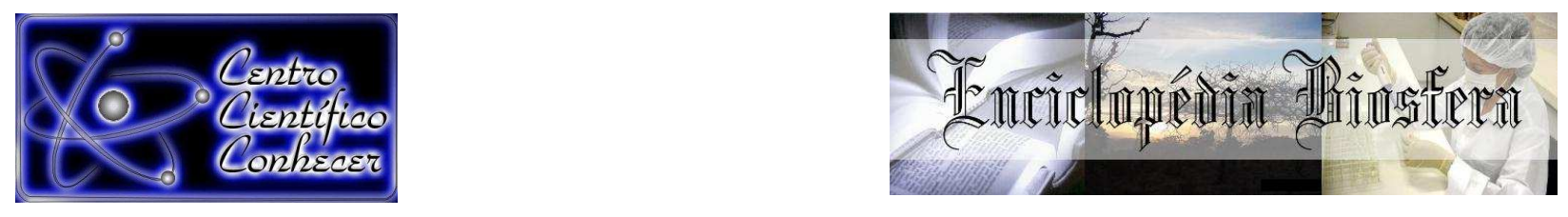

\title{
ESCARIFICAÇÃO MECÂNICA E QUÍMICA NA GERMINAÇÃO DE SEMENTES DE Schinus terebinthifolius Raddi
}

Cleber Witt Saldanha"; Tamires Silveira Moro²; Evandro Luiz Missio1; Joseila Maldaner ${ }^{1}$; Gerusa Pauli Kist Steffen ${ }^{1}$

1. Pesquisador (a) da Fundação Estadual de Pesquisa Agropecuária FEPAGRO - Rio Grande do Sul (clebersaldanha@yahoo.com.br)

2. Bolsista PROBITI FAPERGS/FEPAGRO, Graduanda do curso de Agronomia da Universidade Federal de Santa Maria, RS

Recebido em: 08/04/2017 - Aprovado em: 10/06/2017 - Publicado em: 20/06/2017 DOI: 10.18677/EnciBio_2017A47

\begin{abstract}
RESUMO
A espécie Schinus terebinthifolius Raddi pertencente à família Anacardiaceae ocorre no Brasil desde o estado do Pernambuco até o Rio Grande do Sul. É amplamente utilizada na recomposição de áreas degradadas e arborização urbana, apresenta também importantes propriedades fitoquímicas. Tendo em vista a relevância econômica da espécie, a produção de mudas se torna extremamente importante, entretanto, por apresentar dificuldades de germinação, a propagação é dificultada.

Assim, objetivou-se avaliar diferentes métodos de escarificação mecânica e química no estímulo da germinação de sementes. O delineamento experimental foi 0 inteiramente casualizado, com quatro repetições de 50 sementes em cada tratamento. As avaliações foram realizadas a cada sete dias, durante 28 dias após a inoculação, sendo avaliadas as seguintes características: condutividade elétrica, índice de velocidade de germinação (IVG), primeira contagem de germinação, germinação acumulada, sementes mortas e firmes. A escarificação de sementes de aroeira-vermelha com ácido sulfúrico por 30 minutos ou 30 segundos com lixa P80 oferece novas possibilidades para o aumento da germinação de sementes de $S$. terebinthifolius, podendo ser aplicado por viveiristas para a produção de mudas em larga escala.
\end{abstract}

PALAVRAS-CHAVE: aroeira-vermelha, Anacardiaceae, dormência.

\section{MECHANICAL AND CHEMICAL SCARIFICATION IN SEED GERMINATION OF Schinus terebinthifolius Raddi}

\begin{abstract}
Schinus terebinthifolius Raddi belongs to the Anacardiaceae family, occurs in Brazil from the state of Pernambuco to Rio Grande do Sul. It is widely used in the recovery of degraded areas and urban afforestation, also this species has important phytochemical properties. Considering the economic importance of the species, the production of seedlings it becomes extremely important, however due to have difficulty germination, the propagation is difficult. Thus, the present study aim to evaluate different methods of mechanical and chemistry scarification to promote seed germination. The experimental design was the completely randomized, with four replicates of 50 seeds in each treatment. The evaluations were performed every seven days for 28 days after inoculation and evaluated the following characteristics:
\end{abstract}


electrical conductivity, germination speed index (GSI), first count, accumulated germination, dead and firm seeds. We used 4 replicates, each with 50 seeds in each treatment. The experiments followed a completely randomized design and statistical analysis was performed through the software Sisvar 5.6 at $5 \%$ error probability. Seed scarification in sulfuric acid for 30 minutes or 30 seconds with sandpaper it appears as a new possibility for increasing $S$. terebinthifolius seed germination and can be applied in nurseries for the large scale plants production.

KEYWORDS: Brazilian pepper tree, dormancy, Anacardiaceae

\section{INTRODUÇÃO}

Pertencente à família Anacardiaceae e conhecida popularmente como aroeira-vermelha, a espécie Schinus terebinthifolius Raddi está amplamente distribuída pelo Brasil, ocorrendo em formações vegetais desde Pernambuco até o Rio Grande do Sul e Mato Grosso do Sul, mais comum em beiras de rios. Possui grande importância econômica, já que sua madeira pode ser utilizada para moirões, esteios, lenha e carvão; e ecológica pelo fato de suas sementes serem atrativas aos pássaros (LORENZI, 2000). Por possuir sabor suave, as sementes são utilizadas na culinária mundial, além disso, são aproveitadas na decoração de pratos.

A espécie também possui potencial comercial devido as suas propriedades fitoquímicas, sendo utilizada na medicina popular como antitérmica, analgésica, depurativa e no tratamento de doenças do sistema urogenital. Por outro lado, a literatura científica relata que essa planta apresenta atividade antimicrobiana, antiinflamatória, antiulcerogênica (CARVALHO et al., 2013) e cicatrizante (AZEVEDO et al., 2015). Há registros de testes in vitro sobre o potencial de óleos essenciais de $S$. molle e $S$. terebinthifolius por apresentarem atividade fungicida para Alternaria spp., Botrytis spp., Colleotrichum spp. e Fusarium spp. (SANTOS et al., 2010). Além disso, óleos essenciais de frutos de $S$. terebinthifolius mostraram atividade acaricida (NASCIMENTO et al., 2012).

Acrescenta-se o fato da espécie ser muito utilizada para arborização urbana e recuperação de áreas degradadas (PACHECO et al., 2011). Porém, uma das exigências em programas de restauração florestal de áreas degradadas é o uso de espécies que possuam germinação rápida e uniforme para a produção de mudas (SANTOS et al., 2013). De modo que, a ausência de conhecimento da ecologia da germinação de uma espécie pode ser o principal entrave para a restauração florestal de áreas degradadas (DAYAMBA et al., 2016).

Tendo em vista o potencial da espécie, a propagação de forma rápida e eficiente torna-se fundamental, assim como o conhecimento dos processos fisiológicos da germinação das sementes para otimização da produção de mudas. De acordo com SCALON et al. (2006) a aroeira-vermelha apresenta emergência em 10 a 15 dias com uma taxa de germinação de aproximadamente $50 \%$. Entretanto, sementes de $S$. terebinthifolius em regiões com ocorrência de geadas podem apresentar taxas de germinação inferiores a $50 \%$.

Informações a respeito da superação de dormência e germinação das sementes são fundamentais para o entendimento da biologia da espécie, mas também para realizar a propagação eficiente em condições in situ ou ex situ (BASKIN \& BASKIN, 2005; TRINDADE-LESSA et al., 2015). O conhecimento prático dos processos de superação de dormência de sementes tem grande importância para a restauração e conservação, viabilizando a adequada produção de mudas (PIÑA-RODRIGỦES et al., 2014). 
A dormência em sementes pode ser classificada de forma simplificada em exógena e endógena, sendo possível lançar mão de diversas técnicas para superar as mesmas (BASKIN \& BASKIN, 2014). O uso de tratamentos pré-germinativos quando executados de forma adequada pode viabilizar e favorecer a germinação de sementes de espécies florestais que apresentam dificuldade de germinação (FREIRE et al., 2016). No caso da dormência exógena, técnicas como a escarificação mecânica e ácida podem aumentar os percentuais de germinação de sementes florestais (BASKIN \& BASKIN, 2014).

A germinação e a capacidade de crescimento inicial rápido são características desejáveis de um lote de sementes para as operações de viveiro, sendo que as mesmas têm um forte impacto econômico na margem de lucro do viveirista (STOEHR \& EL-KASSABY, 2011). Desse modo, objetivou-se verificar a técnica de escarificação mecânica e química no estímulo da germinação de sementes de $S$. terebinthifolius, visando a aplicação prática na produção de mudas em viveiro.

\section{MATERIAL E MÉTODOS}

\section{Material vegetal}

As sementes utilizadas nos experimentos foram coletadas de matrizes

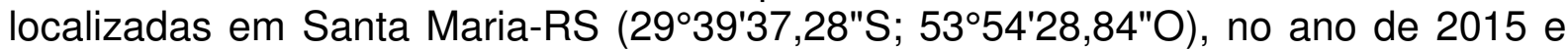
2016. As sementes foram processadas, beneficiadas e armazenadas em câmara fria $\left(8^{\circ} \mathrm{C}\right)$ até a execução dos experimentos.

\section{Escarificação mecânica}

As sementes foram submetidas a diferentes tempos de escarificação: 0,15 , 30 e 45 segundos em tambor rotativo com lixa da marca Rhynolite ${ }^{\circledR} P$ 80. Foram utilizadas 200 sementes (lote 26/15) por tratamento, desinfestadas conforme recomendação do Ministério da Agricultura para análise de sementes florestais (BRASIL, 2013).

Inoculou-se as sementes em caixas do tipo gerbox contendo duas folhas de papel substrato autoclavado, umedecidas com aproximadamente três vezes a sua massa com água destilada e autoclavada. $\mathrm{Na}$ folha superior, foram feitos orifícios para melhor acomodação das sementes. Subsequentemente, as caixas foram levadas ao germinador tipo mangelsdorf a $26^{\circ} \mathrm{C}$. O delineamento experimental foi $\mathrm{O}$ inteiramente casualizado, com quatro repetições de 50 sementes cada.

\section{Escarificação química}

Neste experimento, as sementes foram imersas em recipientes contendo 45 $\mathrm{mL}$ de ácido sulfúrico $\left(\mathrm{H}_{2} \mathrm{SO}_{4}\right)$ durante os tempos de $0,15,30,45$ e 60 minutos. As condições experimentais foram as mesmas descritas no item anterior.

\section{Comparação entre os métodos de escarificação}

Com base nos resultados dos experimentos anteriormente descritos, sementes de aroeira-vermelha (lote 23/16) foram submetidas aos seguintes tratamentos: 1) sementes sem escarificação; 2) 30 segundos de escarificação em lixa e 3) imersão por 30 minutos em ácido sulfúrico. 


\section{Características avaliadas}

As avaliações ocorreram a cada sete dias, durante 28 dias, observando as seguintes características: condutividade elétrica; índice de velocidade de germinação (obtido por meio da fórmula: $\mathrm{Gn} / \mathrm{Nn}$, onde $\mathrm{G}$ é o número de plantas germinadas e $\mathrm{N}$ o número de dias) (MAGUIRE, 1962), primeira contagem e germinação acumulada. No experimento de comparação dos métodos de escarificação foram avaliadas as seguintes características aos sete e aos 14 dias: primeira contagem de germinação; germinação acumulada, sementes mortas e firmes.

\section{Condutividade elétrica}

A determinação da condutividade seguiu recomendações de PIÑARODRIQUES (2004). Para tanto, foram utilizadas 200 sementes, sendo quatro repetições de 50 sementes em frascos de vidro contendo $75 \mathrm{~mL}$ de água desionizada. Os frascos foram mantidos em câmara germinadora tipo mangelsdorf, a $26^{\circ} \mathrm{C}$, no escuro e durante 24 horas. Após esse período, os frascos foram agitados durante 10 segundos e realizada a leitura em condutivímetro Tec- 4MP (Tecnal) com eletrodo de constante 1,0 . O resultado final foi obtido por meio da divisão da massa inicial das sementes pelo resultado da leitura de condutividade e o resultado expresso em $\mu \mathrm{S} \mathrm{cm}^{-1} \mathrm{~g}^{-1}$.

\section{Análise estatística}

As características avaliadas foram submetidas à análise de variância (ANOVA) e posteriormente foram ajustados modelos matemáticos $(p<0,05)$ pela análise de regressão ou realizado o teste de Tukey $(p<0,05)$.

\section{RESULTADOS E DISCUSSÃO}

\section{Escarificação mecânica}

A escarificação das sementes de aroeira-vermelha proporcionou o maior extravasamento de eletrólitos (Figura 1a). Quando as sementes passaram por 45 segundos de escarificação mecânica $\left(578,1 \mu \mathrm{S} \mathrm{cm}^{-1} \mathrm{~g}^{-1}\right)$ apresentaram redução no extravasamento de eletrólitos em relação aquelas escarificadas por 30 segundos $\left(621,8 \mu \mathrm{S} \mathrm{cm}^{-1} \mathrm{~g}^{-1}\right)$. O aumento do extravasamento de eletrólitos em sementes está associado a danos celulares (KAEWNAREE et al., 2011).

Resultados do presente estudo mostraram que sementes de aroeira-vermelha escarificadas durante 15 e 30 segundos (Figura 1b) também apresentaram a maior média de IVG (17,82 e 16,42, respectivamente), indicando que a escarificação permitiu expressar o vigor fisiológico das sementes. Sementes que foram escarificadas por 45 segundos apresentaram redução do índice de velocidade de germinação $(11,22)$, enquanto a testemunha obteve o menor índice $(7,02)$. Outros estudos com sementes de espécies arbóreas, mostraram que a escarificação mecânica de sementes de Macaranga peltata (Roxb.) Mull. Arg. aumentaram 78\% a germinação após a escarificação (RODRIGUES \& RODRIGUES, 2014). Em Cassia fistula L. maior porcentagem de germinação foi observada em sementes escarificadas com lixa d'água ( $n$ 웅) na região lateral (GUEDES et al., 2013).

Sementes que não foram escarificadas apresentaram o valor de $14,04 \%$ para primeira contagem de germinação (Figura 1c). Enquanto que os tratamentos com 
escarificação por 15, 30 e 45 segundos apresentaram 32,84, 35,64 e 22, 44\%, respectivamente, de germinação na primeira contagem (Figura 1c).

As sementes escarificadas durante 15 e 30 segundos (Figura 1d) apresentaram as maiores médias de germinação acumulada (30,76 e 31,06\%, respectivamente). $\mathrm{O}$ tratamento em que as sementes passaram por 45 segundos de escarificação apresentou germinação de 24,97 \%. A redução na porcentagem de germinação entre 30 e 45 segundos de escarificação decorre do aumento de danos mecânicos ao embrião. As sementes que não foram escarificadas apresentaram os menores valores de germinação $(24,52 \%)$. Tais resultados podem ser explicados pelo fato de as sementes permanecerem com o tegumento intacto, o que dificultou a entrada de água e de microrganismos que deterioram o embrião. Além disso, substâncias inibidoras da germinação podem estar presentes na polpa do fruto de algumas espécies de plantas, o que somado às barreiras que dificultam ou impedem a absorção de água pelas sementes, dificultando a germinação (SONI \& SONI, 2010). Desta maneira, a escarificação seria uma alternativa para a diminuição dessas substâncias inibidoras da germinação.
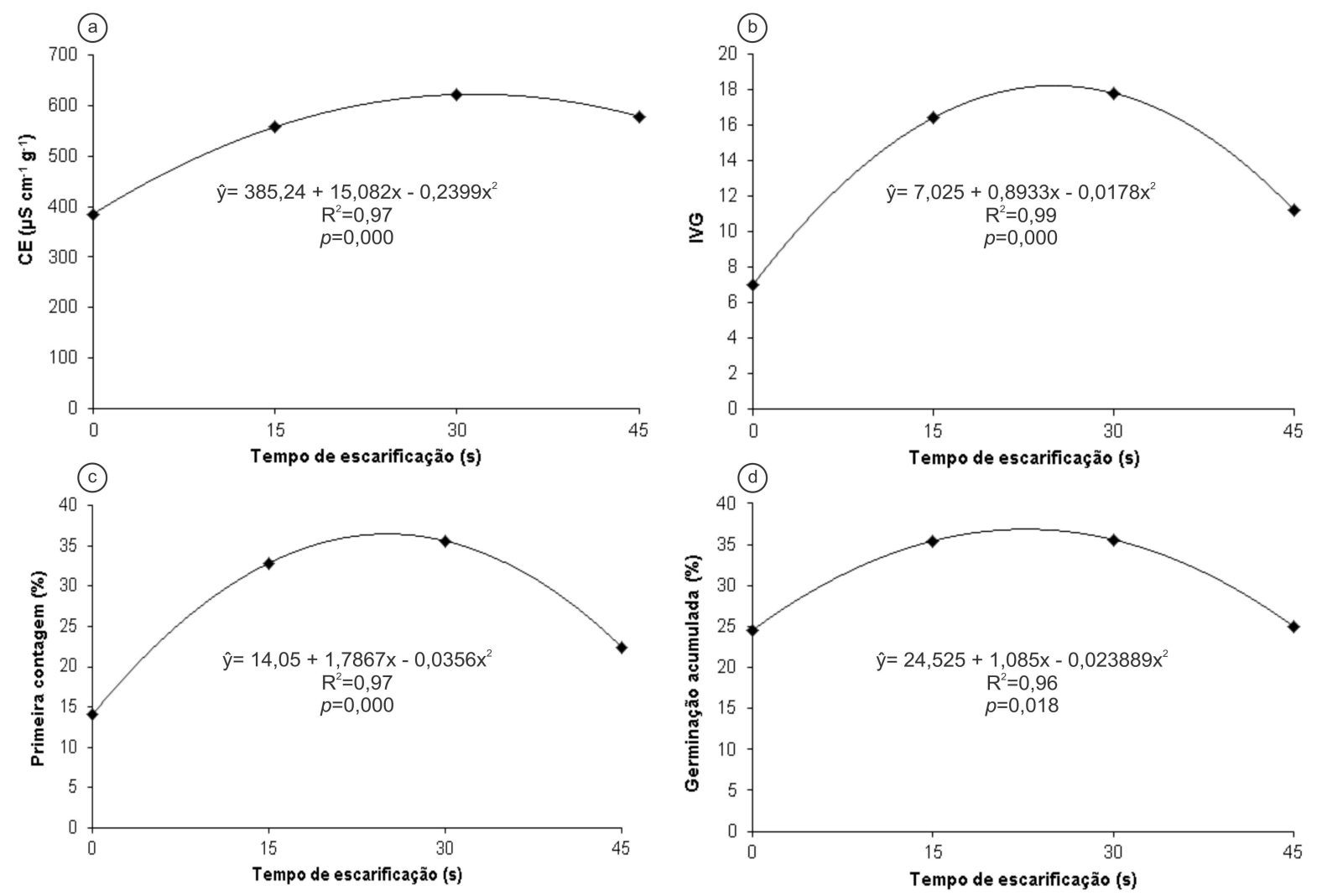

FIGURA 1 - Vigor e germinação de sementes de Schinus terebinthifolius em resposta a diferentes tempos de escarificação mecânica. a) Condutividade elétrica (CE). b) Índice de velocidade de germinação (IVG). c) Primeira contagem de germinação. d) Germinação acumulada.

\section{Escarificação química}

No tratamento em que as sementes foram imersas por 60 minutos em $\mathrm{H}_{2} \mathrm{SO}_{4}$ ocorreu maior lixiviação de eletrólitos $\left(548,8 \mu \mathrm{Sm}^{-1} \mathrm{~g}^{-1}\right)$ em relação aos demais 
tratamentos (Figura 2), a medida que os tempos de exposição das sementes ao ácido foram diminuindo, também ocorreu a redução dos eletrólitos extravasados da semente para o meio. Este resultado mostra que houve maior dano ao tegumento das sementes, podendo ter atingido o embrião e assim, prejudicou a germinação neste tempo de imersão.

Sementes de aroeira-vermelha imersas por $15\left(201,28 \mu \mathrm{S} \mathrm{cm}^{-1} \mathrm{~g}^{-1}\right)$ e 30 $\left(286,07 \mu \mathrm{S} \mathrm{cm} \mathrm{cm}^{-1} \mathrm{~g}^{-1}\right)$ minutos em $\mathrm{H}_{2} \mathrm{SO}_{4}$ apresentaram valores intermediários de extravasamento de eletrólitos (Figura 2). Sementes que não foram imersas em ácido apresentaram o menor valor de condutividade $\left(147,53 \mu \mathrm{S} \mathrm{cm}^{-1} \mathrm{~g}^{-1}\right)$ em função de não haver danos ao tegumento da semente. Resultados semelhantes foram observados em Bauhinia forficata Link, em que a imersão das sementes em ácido sulfúrico por 5 minutos proporcionou o maior valor de condutividade elétrica em relação à testemunha sem superação de dormência e aos demais tratamentos (RONCHI et al., 2016).

Em espécies de plantas, a escarificação com ácido tem sido empregada com sucesso para favorecer a germinação de sementes (MOWA \& MAASS, 2012; CAMPOS et al., 2015; FERNANDES-DE-CAMPOS et al., 2015; KHER \& NATARAJ, 2015; NEGREIROS et al., 2015; MENSAH \& EKEKE, 2016; SANTOS et al., 2016). No presente estudo, sementes de aroeira-vermelha imersas durante 30 minutos em $\mathrm{H}_{2} \mathrm{SO}_{4}$ apresentaram o maior índice de velocidade de germinação $(12,44)$, sendo que os demais tratamentos alcançaram médias inferiores: $15(11,07)$ e 45 minutos $(10,92)$. Os tratamentos sem escarificação $(6,80)$ e 60 minutos $(6,50)$ mostraram as menores médias (Figura 2).
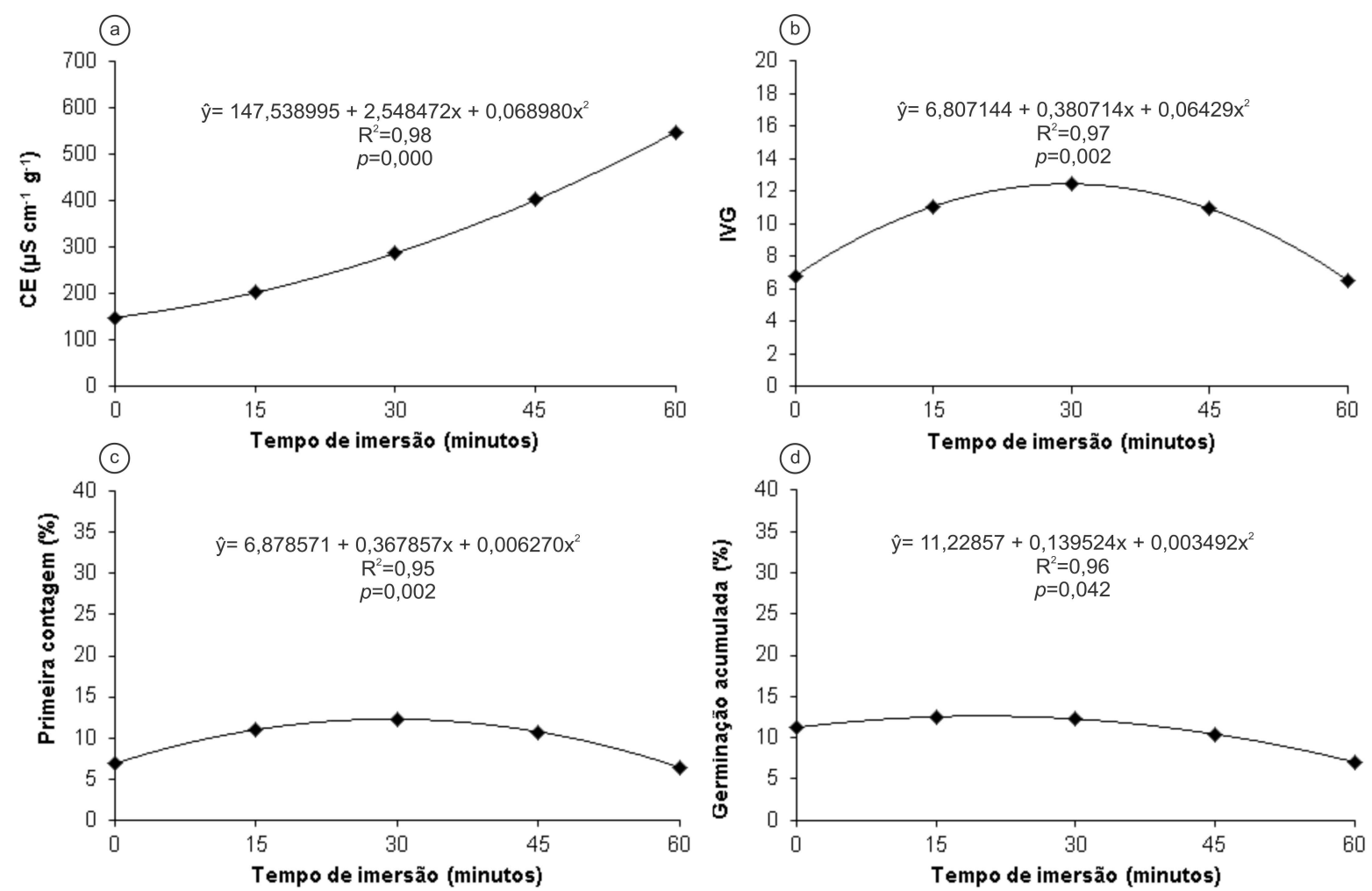

FIGURA 2 - Características de vigor e germinação de sementes de Schinus terebinthifolius em resposta a diferentes tempos de imersão em ácido sulfúrico. a) Condutividade elétrica (CE). b) Índice de velocidade de germinação (IVG). c) Primeira contagem de germinação. d) Germinação acumulada. 
Em C. fistula L. foi observado que sementes submetidas ao tratamento de escarificação com lixa que resultou em maior porcentagem de germinação na primeira contagem e, apresentaram as maiores médias para as demais características avaliadas (GUEDES et al., 2013). No presente estudo, na primeira contagem de germinação foi verificado que ocorreu maior porcentagem de sementes germinadas nos tratamentos em que as sementes foram imersas em ácido sulfúrico por $15(10,9 \%), 30(12,3 \%)$ e 45 minutos (10,7 \%) (Figura 2), apresentando as maiores médias para nos referidos tempos para IVG e germinação acumulada. Sementes sem escarificação e com escarificação por 60 minutos apresentaram as menores médias (6,87 e 6,37\%, respectivamente) de germinação na primeira contagem.

As maiores médias de germinação acumulada foram observadas no tratamento de imersão das sementes por 15 minutos em $\mathrm{H}_{2} \mathrm{SO}_{4}(12,53 \%)$ e por 30 minutos $(12,27 \%)$ (Figura 2). Quando as sementes foram imersas por 45 minutos $(10,43 \%)$ e 60 minutos $(7,02 \%)$ em ácido sulfúrico a germinação foi reduzida em relação aos demais tratamentos. A redução na porcentagem de germinação em resposta ao aumento do tempo de escarificação com ácido pode estar relacionada a danos causados no embrião (FERNANDES-DE-CAMPOS et al., 2015).

\section{Comparação entre os métodos de escarificação}

A comparação entre os tipos de escarificação mostrou que tanto o uso da lixa quanto a imersão em ácido sulfúrico aumentaram a germinação das sementes de aroeira-vermelha em relação às sementes sem escarificação (Tabela 1). Os tipos de escarificação não diferiram entre si em todas as características avaliadas, porém diferiram da testemunha. Os valores mostram que ambos os métodos são eficientes para promoção da germinação de aroeira-vermelha.

A aroeira-vermelha é apontada como uma espécie arbórea que não precisa de tratamento para a superação de dormência (CARVALHO, 2003), entretanto, nas condições de execução do presente estudo ficou evidente que a escarificação (química ou mecânica) favorece a germinação das sementes de aroeira-vermelha. Resultados semelhantes foram observados para Bixa orellana L. em que as escarificações química com ácido sulfúrico ou mecânica com lixa aumentaram a taxa de germinação em relação às sementes que não foram escarificadas (PICOLOTTO et al., 2013). Por outro lado, em Guazuma ulmifolia a escarificação mecânica não foi a melhor alternativa para a superação da dormência tegumentar, sendo a escarificação térmica a melhor alternativa (SILVA et al., 2016).

TABELA 1 - Comportamento da germinação de sementes de Schinus terebinthifolius em resposta a diferentes tratamentos de escarificação.

\begin{tabular}{ccccc}
\hline Tratamentos & $\begin{array}{c}\text { Primeira } \\
\text { contagem (\%) }\end{array}$ & $\begin{array}{c}\text { Germinação } \\
\text { acumulada (\%) }\end{array}$ & $\begin{array}{c}\text { Sementes } \\
\text { mortas (\%) }\end{array}$ & $\begin{array}{c}\text { Sementes } \\
\text { firmes (\%) }\end{array}$ \\
\hline Testemunha & $28,50 \mathrm{~b}^{*}$ & $38,50 \mathrm{~b}$ & $0,00 \mathrm{~b}$ & $61,50 \mathrm{a}$ \\
Lixa P80 & $56,50 \mathrm{a}$ & $68,50 \mathrm{a}$ & $7,0 \mathrm{a}$ & $24,50 \mathrm{~b}$ \\
$\mathrm{H}_{2} \mathrm{SO}_{4}$ & $59,50 \mathrm{a}$ & $75,50 \mathrm{a}$ & $11,0 \mathrm{a}$ & $13,50 \mathrm{~b}$ \\
$\cdots \mathrm{CV}^{* *}(\%)$ & 19,68 & 11,71 & 41,57 & 20,52 \\
\hline
\end{tabular}

${ }^{\star}$ Médias nas colunas seguidas de mesma letra não diferem pelo Teste de Tukey $(p<0,05){ }^{* *} \mathrm{CV}$ : Coeficiente de variação. 
Contudo, tendo em vista a dificuldade de manipulação e descarte do ácido, uso da escarificação em tambor rotativo, com lixa P80, simplifica e facilita o processo, garantindo bons resultados de germinação e vigor. Estudos ressaltam que o método de escarificação adequado deve favorecer a germinação e manter o vigor durante a germinação (CAMPOS et al., 2015; PEREIRA et al., 2016), possibilitando ganhos no manejo em viveiro, através da diminuição do tempo entre a semeadura e emergência da plântula (MISSIO et al., 2016).

\section{CONCLUSÃO}

A escarificação de sementes com ácido sulfúrico por 30 minutos ou 30 segundos com lixa favorece a germinação de $S$. terebinthifolius em condições de laboratório.

A comparação entre a escarificação ácida e mecânica apresentou resultados semelhantes em ambas às técnicas para as características avaliadas, podendo o viveirista optar pelo método que melhor atender sua demanda.

\section{REFERÊNCIAS}

AZEVEDO, C. F., QUIRINO, Z. G. M.; BRUNO, R. L. A. Estudo farmacobotânico de partes aéreas vegetativas de aroeira-vermelha (Schinus terebinthifolius Raddi, Anacardiaceae). Revista Brasileira de Plantas Medicinais, v.17, n.1, p.26-35, 2015. Disponível em: <http://dx.doi.org/10.1590/1983-084X/11_090>. doi: 10.1590/1983-084X/11_090

BASKIN, C. C.; BASKIN, J. M. Seed dormancy in trees of climax tropical vegetation types. Tropical Ecology, v.46, n.1, p.17-28, 2005. Disponível em: < http://www.tropecol.com/pdf/open/PDF_46_1/46102.pdf>.

BASKIN, C. C.; BASKIN, J. M. Seeds: Ecology, Biogeography, and Evolution of Dormancy and Germination. San Diego, CA, USA: Elsevier/Academic Press. Second edition. 2014.

BRASIL. Instruções para análises de sementes de espécies florestais. 97p. 2013. Disponível em: < http://www.agricultura.gov.br/arq_editor/file/Laboratorio/Sementes/FLORESTAL_doc umento_pdf.pdf>

CAMPOS, L. F. C.; ABREU, C. M.; GUIMARÃES, R. N.; SELEGUINI, A. Escarificação e ácido giberélico na emergência e crescimento de plântulas de biribá.

Ciência Rural, v.45, n.10, p.1748-1754, 2015. Disponível em: <http://dx.doi.org/10.1590/0103-8478cr20140249>. doi: 10.1590/01038478 cr20140249

CARVALHO, P. E. R. Espécies arbóreas brasileiras. Colombo: Embrapa Florestas, 2003. 1 v. 1039 p.

CARVALHO, M. G.; MELO, A. G. N.; ARAGÃO, C. F. S.; RAFFIN, F. N.; MOURA, T. F. A. L. Schinus terebinthifolius Raddi: chemical composition, biological properties 
and toxicity. Revista Brasileira de Plantas Medicinais, v.15, n.1, p.158-169, 2013. Disponível em: <http://dx.doi.org/10.1590/S1516-05722013000100022>. doi: $10.1590 /$ S1516-05722013000100022

DAYAMBA, S. D.; SAVADOGO, P.; DIAWARA, S.; SAWADOGO, L. Perspectives in restoration: storage and pretreatments of seeds for better germination of Sudanian savanna-woodland species. Journal of Forestry Research, v.27, n.4, p.773-778, 2016. Disponível em: <http://link.springer.com/article/10.1007/s11676-016-0220-7>. doi: 10.1007/s11676-016-0220-7

FERNANDES-DE-CAMPOS, K. A.; SAPATINI, J. R.; PEDROSO-DE-MORAES, C. Superação de dormência em sementes de Bombax malabaricum D.C. (Malvaceae). Revista Brasileira de Plantas Medicinais, v.17, n.4, p.515-520, 2015. Disponível em: <http://dx.doi.org/10.1590/1983-084X/12_175>. doi: 10.1590/1983-084X/12_175

FREIRE, M. J.; ATAÍDE, D. H. S.; ROUWS, J. R. C. Superação de Dormência de Sementes de Albizia pedicellaris (DC.) L. Rico. Floresta e Ambiente, v.23, n.2, p. 251-257, 2016. Disponível em: <http://www.scielo.br/pdf/floram/2016nahead/21798087-floram-2179-8087104514.pdf>. doi: 10.1590/2179-8087.104514

GUEDES, R. S.; ALVES, E. U.; SANTOS-MOURA, S. S.; COSTA, E. G.; MELO, P. A. F. R. Tratamentos para superar dormência de sementes de Cassia fistula $L$. Biotemas, v.26, n.4, p.11-22, 2013. Disponível em: < https://periodicos.ufsc.br/index.php/biotemas/article/viewFile/2175-

7925.2013v26n4p11/25695>. doi: 10.5007/2175-7925.2013v26n4p11

KAEWNAREE, P.; VICHITPHAN, S.; KLANRIT, P.; SIRI, B.; VICHITPHAN. K. Effect of accelerated aging process on seed quality and biochemical changes in sweet pepper (Capsicum annuum Linn.) seeds. Biotechnology, v.10, n.2, p.175-182, 2011. Disponível em: < http://dx.doi.org/10.3923/biotech.2011.175.182>. doi: 10.3923/biotech.2011.175.182

KHER, M. M.; NATARAJ, M. Effect of sulfuric acid treatment on breaking of seed dormancy and germination of Indian doum palm, Hyphaene dichotoma, a threatened and endemic palm. Environmental and Experimental Biology, v.13, n.3, p.99-101, 2015. Disponível em: < http://eeb.lu.Iv/EEB/201510/EEB_13_Kher.pdf>.

LORENZI, H. Árvores Brasileiras: manual de identificação e cultivo de plantas arbóreas nativas do Brasil. Nova Odessa, São Paulo: Instituto Plantarum, v. 1, 368p. 2000.

MAGUIRE, J. D. Speed of germination-aid in selection and evaluation for seedling emergence and vigor. Crop Science, v.2, n.1, p.176-177, 1962. Disponível em: <https://dl.sciencesocieties.org/publications/cs/abstracts/2/2/CS0020020176>. doi: 10.2135/cropsci1962.0011183X000200020033x

MENSAH, S. I.; EKEKE, C. Effects of different pretreatments and seed coat on dormancy and germination of seeds of Senna obtusifolia (L.) H.S. Irwin \& Barneby 
(Fabaceae). International Journal of Biology, v.8, n.2, p.77-84, 2016. Disponível em: <http://dx.doi.org/10.5539/ijb.v8n2p77>. doi: 10.5539/ijb.v8n2p77

MISSIO, E. L.; SALDANHA, C. W.; MALDANER, J.; MORAIS, R. M.; STEFFEN, G. Escarificação mecânica em cilindro rotativo é viável para a superação da dormência de sementes de pau-ferro. Enciclopédia Biosfera, v.13, n.24, p.476-485, 2016. Disponível em:

http://www.conhecer.org.br/enciclop/2016b/agrarias/escarificacao.pdf>.

doi: 10.18677/EnciBio_2016B_043

MOWA, E.; MAASS, E. The effect of sulphuric acid and effective micro-organisms on the seed germination of Harpagophytum procumbens (devil's claw). South African Journal of Botany, v.83, p.193-199, 2012. Disponível em: < http://www.sciencedirect.com/science/article/pii/S025462991200066X>. doi: 10.1016/j.sajb.2012.05.006

NASCIMENTO, A. F.; CAMARA, C. A. G.; MORAES, M. M.; RAMOSA, C. S. Essential oil composition and acaricidal activity of Schinus terebinthifolius from atlantic forest of Pernambuco, Brazil against Tetranychus urticae. Natural Product Communications, v.7, n.1, p.129-132, 2012. Disponível em: < https://www.researchgate.net/publication/221720981_Essential_Oil_Composition_an d_Acaricidal_Activity_of_Schinus_terebinthifolius_from_Atlantic_Forest_of_Pernamb uco_Brazil_against_Tetranychus_urticae>.

NEGREIROS, J. M. M.; FEITOSA, A. A. N.; OLIVEIRA, S. S.; FERREIRA, J. B.; NASCIMENTO, G. O. Superação de dormência em sementes de Schizolobium amazonicum Ducke. Enciclopédia Biosfera, v.11, n.22, p.254-262, 2015. Disponível em: < http://dx.doi.org/10.18677/Enciclopedia_Biosfera_2015_227>. doi: 10.18677/Enciclopedia_Biosfera_2015_227

PACHECO, M. V.; SILVA, C. S.; SILVEIRA, T. M. T.; HÖLBIG, L. S.; HARTER, F. S.; VILLELA, F. A. Physiological quality evaluation of the radii Schinus terebinthifolius seeds. Revista Brasileira de Sementes, v.33, n.4, p.762-767, 2011. Disponível em: < http://dx.doi.org/10.1590/S0101-31222011000400018>. doi: 10.1590/S010131222011000400018

PEREIRA, M. P.; CORRÊA, F. F.; POLO, M.; CASTRO, E. M.; CARDOSO, A. A.; PEREIRA, F. J. Seed germination of Schinus molle L. (Anacardiaceae) as related to its anatomy and dormancy alleviation. Seed Science Research, v.26, n.4, p.351361, 2016. Disponível em: <http://dx.doi.org/10.1017/S0960258516000167>. doi: $10.1017 /$ S0960258516000167

PICOLOTTO, D. R. N.; THEODORO, J. V. C.; DIAS, A.R.; THEODORO, G. F.; ALVES, C. Z. Germinação de sementes de urucum em função de métodos de superação de dormência e temperaturas. Pesquisa Agropecuária Tropical, v.43, n.3, p.232-238, 2013. Disponível em: <http://www.scielo.br/pdf/pat/v43n3/a04.pdf>. 
PIÑA-RODRIGUES, F. C. M.; FIGLIOLIA, M. B.; PEIXOTO, M. C. Testes de qualidade. In: FERREIRA, A. G.; BORGHETTI, F. (Org.). Germinação: do básico ao aplicado. Porto Alegre: Artmed, 2004. p. 283-297.

PIÑA-RODRIGUES, F. C. M.; FREIRE, J. M.; ROLIM, S. G.; JESUS, R. M. de; GRIMALDI, M. C. Maturação e dormência de sementes florestais nativas para a restauração: 20 anos de experiência na reserva natural Vale Linhares, Espirito Santo. Ciência \& Ambiente, v. 49, p.131-152, 2014.

RODRIGUES, C. R.; RODRIGUES, B. F. Enhancement of seed germination in Macaranga peltata for use in tropical forest restoration. Journal of Forestry Research, v.25, n.4, p.897-901, 2014. Disponível em: < http://link.springer.com/article/10.1007/s11676-014-0536-0>. doi: 10.1007/s11676014-0536-0

RONCHI, H. S.; BONFIM, F. P. G.; HONÓRIO, I. C. G.; CAPAZ, R. P. S.; HERNANDES, I. B. Superação de dormência tegumentar de sementes da pata de vaca (Bauhinia forficata Link). Enciclopédia Biosfera, v.13 n.23; p.1291-1297, 2016. Disponível em: <http://dx.doi.org/10.18677/Enciclopedia_Biosfera_2016_114. doi: 10.18677/Enciclopedia_Biosfera_2016_114

SANTOS, A. C. A.; ROSSATO, M.; SERAFINI, L. A.; BUENO, M.; CRIPPA, L. B.; SARTORI, V. C.; DELLACASSA, E.; MOYNA, P. Efeito fungicida dos óleos essenciais de Schinus molle L. e Schinus terebinthifolius Raddi, Anacardiaceae, do Rio Grande do Sul. Brazilian Journal of Pharmacognosy, v.20, n.2, p.154-159, 2010. Disponível em: <http://dx.doi.org/10.1590/S0102-695X2010000200003>. doi: $10.1590 /$ S0102-695X2010000200003

SANTOS, L. W.; COELHO, M. F. B.; MAIA, S. S. S.; SILVA, R. C. P.; CÂNDIDO, W. S.; SILVA, A. C. Armazenamento e métodos para a superação da dormência de sementes de mulungu. Semina: Ciências Agrárias, v.34, n.1, p.171-178, 2013. Disponível em: <http://www.uel.br/revistas/wrevojs248/index.php/semagrarias/article/view/8187/1202 1>. doi: 10.5433/1679-0359.2013v34n1p171

SANTOS, S. R.; OLIVEIRA, R. S. S. F.; SOUZA, L. C.; SILVA, S. D. S. R. Tratamentos pré-germinativos para sementes de Hymenaea stigonocarpa Mart. ex Hayne. Biotemas, v.29,n. 4, p.1-8, 2016. Disponível em: < https://periodicos.ufsc.br/index.php/biotemas/article/view/2175-7925.2016v29n4p1>. doi: 10.5007/2175-7925.2016v29n4p1

SCALON, S. P. Q.; MUSSURY, R. M.; FILHO; H. S.; FRANCELINO, C. S. F. Desenvolvimento de mudas de Aroeira (Schinus terebinthifolius) e sombreiro (Clitoria fairchildiana) sob condições de sombreamento. Ciência e Agrotecnologia, v.30, n.1, p.166-169, 2006. Disponível em: <http://dx.doi.org/10.1590/S141370542006000100024>. doi: 10.1590/S1413-70542006000100024

SILVA, D. L.; LUZ, G. R.; VELOSO, M. D. M.; FERNANDES, G. W.; NUNES, Y. R. F. Emergência e estabelecimento de plântulas de Guazuma ulmifolia Lam. em função 
de diferentes tratamentos pré-germinativos. Ciência Florestal, v.26, n.3, p.763-772, 2016. Disponível em: < https://periodicos.ufsm.br/cienciaflorestal/article/view/24205>. doi: $10.5902 / 1980509824205$

STOEHR, M. U.; EL-KASSABY, Y. A. Challenges Facing the Forest Industry in Relation to Seed Dormancy and Seed Quality. In.: KERMODE, A. R. (ed.). Seed Dormancy: Methods and Protocols, Methods in Molecular Biology, vol. 773, 2011. DOI: 10.1007/978-1-61779-231-1_1

SONI, N. K.; SONI, V. Fundamentals of Botany. Volume 2. Tata McGraw-Hill Education Pvt. Ltd., 2010.

TRINDADE-LESSA, B. F.; J. ALMEIDA, P. N.; LOBO-PINHEIRO, C.; MELOGOMES, F.; MEDEIROS-FILHO, S. Germination and seedling growth of Enterolobium Contortisiliquum as a function of seed weight and temperature and light conditions. Agrociência, v.49, n.3, p.315-327, 2015. Disponível em: <http://www.scielo.org.mx/pdf/agro/v49n3/v49n3a7.pdf>. 